\title{
Hypersecretion of ACTH and PRL from pituitary adenoma in MEN1, adequately managed by medical therapy
}

\author{
Shinsuke Uraki', Hiroyuki Ariyasu', Asako Doi', Hiroto Furuta', Masahiro Nishi', \\ Takeshi Usui², Hiroki Yamaue ${ }^{3}$ and Takashi Akamizu ${ }^{1}$ \\ 1The 1st Department of Internal Medicine, Wakayama Medical University, Wakayama, Japan, ${ }^{2}$ Department of \\ Medical Genetics, Shizuoka General Hospital, Shizuoka City, Japan, and ${ }^{3}$ The 2nd Department of Surgery, \\ Wakayama Medical University, Wakayama, Japan
}

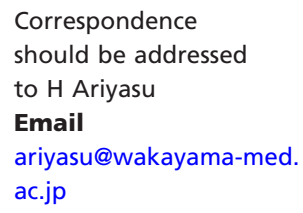

\section{Summary}

A 54-year-old man had gastrinoma, parathyroid hyperplasia and pituitary tumor. His family history indicated that he might have multiple endocrine neoplasia type 1 (MEN1). MEN1 gene analysis revealed a heterozygous germline mutation (Gly156Arg). Therefore, we diagnosed him with MEN1. Endocrinological tests revealed that his serum prolactin (PRL) and plasma adrenocorticotropic hormone (ACTH) levels were elevated to $1699 \mathrm{ng} / \mathrm{mL}$ and $125 \mathrm{pg} / \mathrm{mL}$ respectively. Immunohistochemical analysis of the resected pancreatic tumors revealed that the tumors did not express ACTH. Overnight 0.5 and $8 \mathrm{mg}$ dexamethasone suppression tests indicated that his pituitary tumor was a PRL-ACTH-producing plurihormonal tumor. Before transsphenoidal surgery, cabergoline was initiated. Despite no decrease in the volume of the pituitary tumor, PRL and ACTH levels decreased to $37.8 \mathrm{ng} / \mathrm{mL}$ and $57.6 \mathrm{pg} / \mathrm{mL}$ respectively. Owing to the emergence of metastatic gastrinoma in the liver, octreotide was initiated. After that, PRL and ACTH levels further decreased to $5.1 \mathrm{ng} / \mathrm{mL}$ and $19.7 \mathrm{pg} / \mathrm{mL}$ respectively. He died from liver dysfunction, and an autopsy of the pituitary tumor was performed. In the autopsy study, histopathological and immunohistochemical (IHC) analysis showed that the tumor was single adenoma and the cells were positive for ACTH, growth hormone (GH), luteinizing hormone (LH) and PRL. RT-PCR analysis showed that the tumor expressed mRNA encoding all anterior pituitary hormones, pituitary transcription factor excluding estrogen receptor (ER) $\beta$, somatostatin receptor (SSTR) 2, SSTR5 and dopamine receptor D (D2R). PRL-ACTH-producing tumor is a very rare type of pituitary tumor, and treatment with cabergoline and octreotide may be useful for controlling hormone levels secreted from a plurihormonal pituitary adenoma, as seen in this case of MEN1.

\section{Learning points:}

- Although plurihormonal pituitary adenomas were reported to be more frequent in patients with MEN1 than in those without, the combination of PRL and ACTH is rare.

- RT-PCR analysis showed that the pituitary tumor expressed various pituitary transcription factors and IHC analysis revealed that the tumor was positive for PRL, ACTH, GH and LH.

- Generally, the effectiveness of dopamine agonist and somatostatin analog in corticotroph adenomas is low; however, if the plurihormonal pituitary adenoma producing ACTH expresses SSTR2, SSTR5 and D2R, medical therapy for the pituitary adenoma may be effective. 


\section{Background}

Multiple endocrine neoplasia type 1 (MEN1) is an autosomal dominant inherited disease characterized by parathyroid hyperplasia, endocrine enteropancreatic tumors and pituitary adenomas. Anterior pituitary tumors occur in approximately $35-40 \%$ of patients with MEN1 $(1,2)$. Prolactinoma, present in $63 \%$ of these patients, is the most common subtype of pituitary tumor in MEN1 (2), followed by non-functioning tumor (15\%), GH-producing tumor (10\%) and ACTH-producing tumor (4\%). PRL is frequently co-produced with GH in the same pituitary tumor (3), and there are several reports of co-secretion of PRL-GH-TSH (thyroid-stimulating hormone), GH-TSH, PRL-TSH and PRL-ACTH (4). Although these mixed pituitary adenomas were reported to be more frequent in patients with MEN1 than in those without, excessive secretion of PRL and ACTH from pituitary adenoma is rare $(2,5)$.

Here, we describe a MEN1 patient with rare pituitary macroadenoma with excessive PRL and ACTH secretion. His hyper-PRL-ACTH-nemia was normalized by treatment with dopamine agonist (cabergoline) and long-acting analog of somatostatin (octreotide).

\section{Case presentation}

A 54-year-old man was referred to the Wakayama Medical University Hospital because of hypergastrinemia and suspicion of pancreatic tumors. He had been affected by perforated duodenal ulcer and treated with omental implantation 1 month before arriving at our hospital. Family history revealed that he had two older brothers who died from pancreatic tumor at the ages of 67 and 30 years respectively. He had three sons and two of them (aged 28 and 21 years) suffered from pancreatic neuroendocrine tumor (pNET) (Fig. 1). The results of biochemical and endocrinological tests are shown in Table 1. Serum calcium (Ca) and ionized calcium levels were near the upper limit of the reference range, and serum intact parathyroid hormone (iPTH) levels were elevated. Plasma gastrin levels were elevated to $1.878 \mathrm{pg} / \mathrm{mL}$, although the patient was receiving medication with a proton pump inhibitor. In addition, serum PRL and plasma ACTH levels were also elevated to $1.699 \mathrm{ng} / \mathrm{mL}$ and $125 \mathrm{pg} / \mathrm{mL}$ respectively. On physical examination, he exhibited hyperpigmentation, but did not have symptoms of hyperprolactinemia or Cushingoid features; his body mass index was $20.5 \mathrm{~kg} / \mathrm{m}^{2}$ (HT: $185 \mathrm{~cm}$, BW: $70 \mathrm{~kg}$ ), blood pressure was $112 / 70 \mathrm{mmHg}$ and $\mathrm{HbA} 1 \mathrm{c}$ was

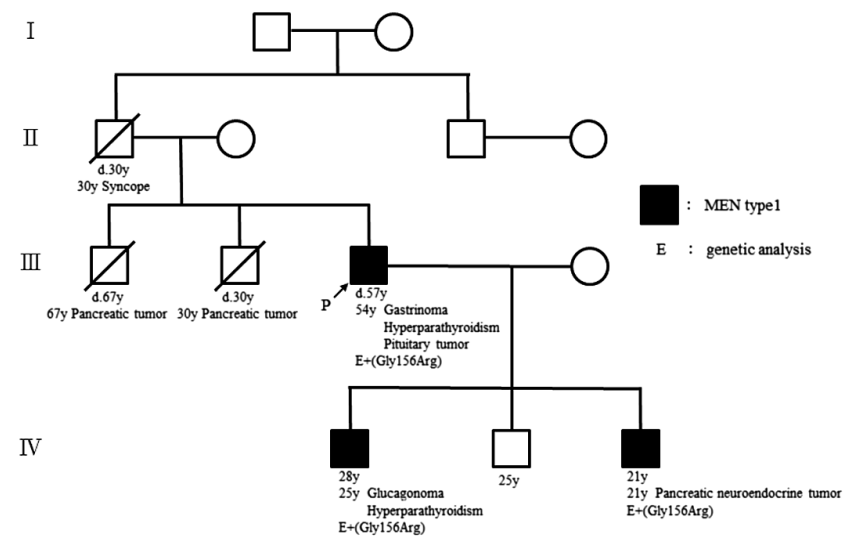

Figure 1

Pedigree of the patient.

5.4\%. Abdominal computer tomography (CT) identified multiple early enhancing pancreatic tumors (at least three tumors) and bilateral adrenal swelling (Fig. 2A). Carotid CT and ultrasound examinations detected the enlargement of three parathyroid glands (data

Table 1 Laboratory investigations at presentation.

\begin{tabular}{|c|c|c|c|}
\hline Investigations & Units & Values & Reference range \\
\hline $\mathrm{GH}$ & $\mathrm{ng} / \mathrm{mL}$ & 0.7 & $0-2.1$ \\
\hline PRL & $\mathrm{ng} / \mathrm{mL}$ & 1699.1 & \\
\hline LH & IU/mL & 2.3 & $>4$ \\
\hline FSH & $\mathrm{IU} / \mathrm{mL}$ & 12.4 & $>15$ \\
\hline TSH & $\mu \mathrm{IU} / \mathrm{mL}$ & 0.59 & $0.35-4.94$ \\
\hline Free T3 & $\mathrm{pg} / \mathrm{mL}$ & 2.34 & $1.71-3.71$ \\
\hline Free T4 & $\mathrm{ng} / \mathrm{dL}$ & 0.92 & $0.70-1.48$ \\
\hline ACTH & $\mathrm{pg} / \mathrm{mL}$ & 125.9 & 7.2-63.3 \\
\hline Cortisol & $\mu \mathrm{g} / \mathrm{dL}$ & 12.9 & 2.9-19.4 \\
\hline IGF-1 & $\mathrm{ng} / \mathrm{mL}$ & 304.4 & $83-237$ \\
\hline Gastrin & $\mathrm{pg} / \mathrm{mL}$ & 1878 & $42-200$ \\
\hline PTH-intact & $\mathrm{pg} / \mathrm{mL}$ & 242 & $10-65$ \\
\hline $\mathrm{Ca}^{2+}$ & $\mathrm{mEq} / \mathrm{L}$ & 2.6 & $2.1-2.5$ \\
\hline $\mathrm{Ca}$ & $\mathrm{mg} / \mathrm{dL}$ & 10.9 & $8.7-11$ \\
\hline IP & $\mathrm{mg} / \mathrm{dL}$ & 2.7 & $2.5-4.5$ \\
\hline Alb & $\mathrm{g} / \mathrm{dL}$ & 3.7 & $3.8-5.1$ \\
\hline WBC & $10^{2} / \mu \mathrm{L}$ & 66.4 & 35-98 \\
\hline Neutrophil & $\%$ & 67.8 & \\
\hline Eosinophil & $\%$ & 2.4 & \\
\hline Lymphocyte & $\%$ & 22.3 & \\
\hline PG & $\mathrm{mg} / \mathrm{dL}$ & 132 & $60-100$ \\
\hline HbA1c & $\%$ & 5.4 & $4.7-6.2$ \\
\hline IRI & $\mu U / m L$ & 15.6 & $1.1-17$ \\
\hline Triglyceride & $\mathrm{mg} / \mathrm{dL}$ & 73 & $30-150$ \\
\hline Total-cholesterol & $\mathrm{mg} / \mathrm{dL}$ & 146 & $150-219$ \\
\hline $\mathrm{Na}$ & $\mathrm{mEq} / \mathrm{L}$ & 142 & $135-145$ \\
\hline $\mathrm{K}$ & $\mathrm{mEq} / \mathrm{L}$ & 4.7 & $3.5-5.0$ \\
\hline $\mathrm{Cl}$ & $\mathrm{mEq} / \mathrm{L}$ & 106 & 98-107 \\
\hline
\end{tabular}

$\mathrm{GH}$, growth hormone; $\mathrm{PRL}$, prolactin; $\mathrm{LH}$, luteinizing hormone; $\mathrm{FSH}$, follicle-stimulating hormone; TSH, thyroid stimulating hormone; $\mathrm{ACTH}$, adrenocorticotropic hormone; IGF-1, insulin-like growth factors-1; PTH, parathyroid hormone; PG, plasma glucose; IRI, immunoreactive insulin. 

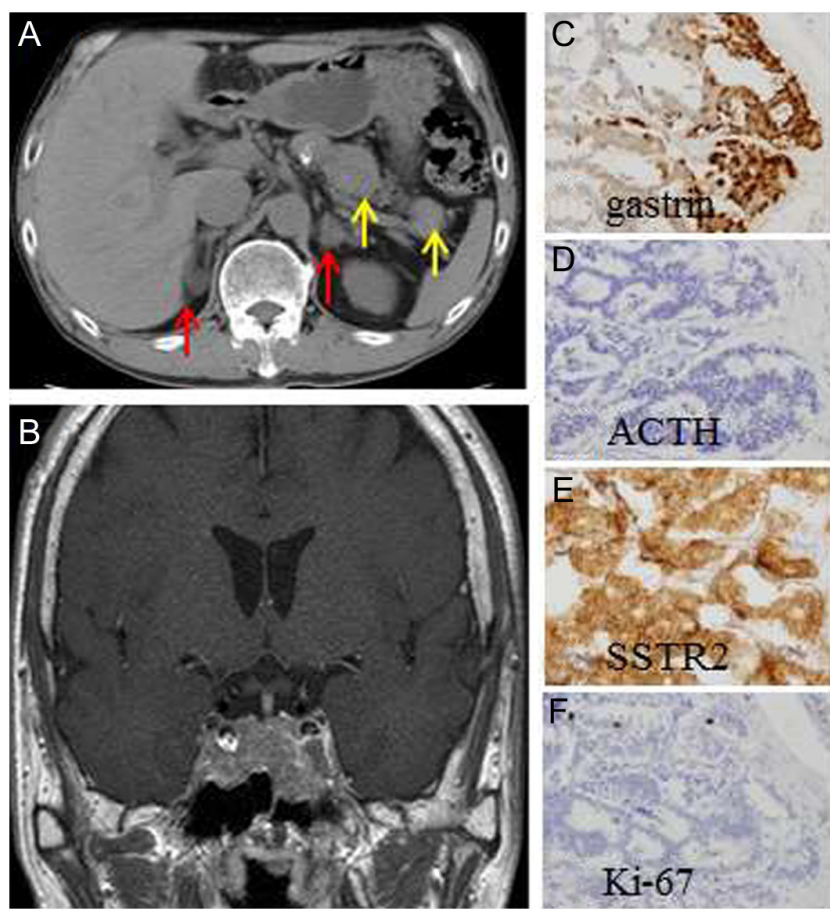

Figure 2

Images of the abdomen and pituitary, and immunohistochemistry of the pancreatic tumor. (A) Computed tomography of the abdomen; multiple pancreatic tumors and bilateral adrenal swelling were identified. (B) MRI of the pituitary gland. (C, D, E and F) Immunohistochemical analysis of the resected pancreas tumor.

not shown). Contrast-enhanced magnetic resonance imaging (MRI) of the pituitary identified a pituitary tumor with invasion of both right and left cavernous sinuses, suggesting that the pituitary tumor may be single adenoma and not multiple (Fig. 2B). Taking his family history and these results into account, he was strongly suspected of having MEN1. As described below, the diagnosis of MEN1 was eventually confirmed by genetic analysis. Although we could not measure urinary cortisol excretion, elevation of plasma ACTH levels and bilateral adrenal swelling suggested an overproduction of ACTH. Therefore, we performed further examination on the ACTH-adrenal axis. After oral administration of dexamethasone at a dose of $0.5 \mathrm{mg}$, midnight serum

Table 2 Diurnal variation and 0.5-mg or 8.0-mg dexamethasone suppression test of ACTH and cortisol.

\begin{tabular}{|c|c|c|c|c|c|}
\hline & \multicolumn{3}{|c|}{$\begin{array}{c}\text { Diurnal variation } \\
\text { (time) }\end{array}$} & \multicolumn{2}{|c|}{$\begin{array}{l}\text { Dexamethasone } \\
\text { suppression test }\end{array}$} \\
\hline & 7:00 & $16: 00$ & $23: 00$ & $0.5 \mathrm{mg}$ & $8 \mathrm{mg}$ \\
\hline$\overline{\text { ACTH }(p g / m L)}$ & 81.1 & 68.2 & 79.5 & 110.7 & 35.4 \\
\hline Cortisol ( $\mu \mathrm{g} / \mathrm{dL})$ & 11.6 & 11.7 & 11.2 & 11.7 & 1.4 \\
\hline
\end{tabular}

Reference range: ACTH 7.2-63.3 pg/mL, cortisol 2.9-19.4 $\mu \mathrm{g} / \mathrm{dL}$.
A
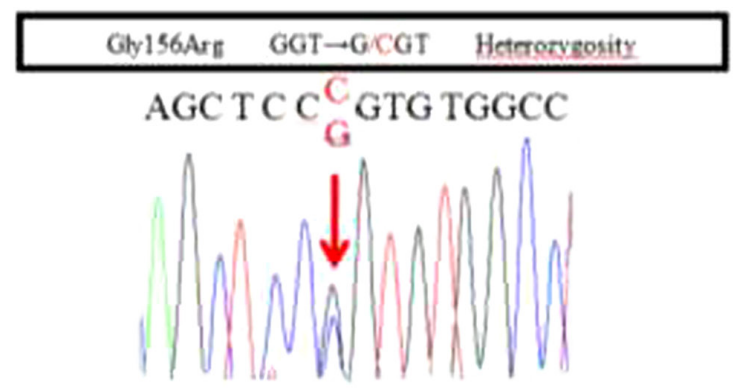

B

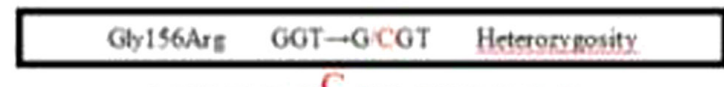

AGC T C C ${ }_{G}^{\mathrm{C}}$ GT GTGG C C

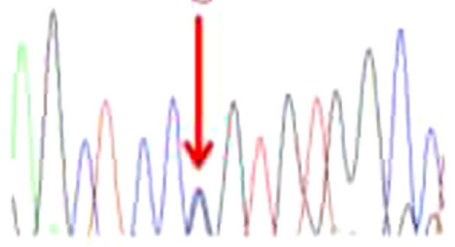

C

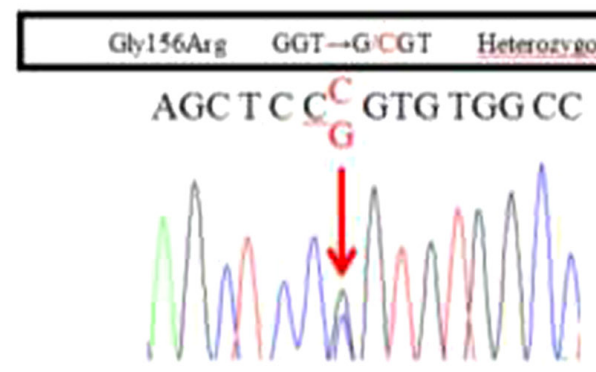

D

Gly156Ars GOT - COT Loss of Heterorngosity

AGC T CCCGT GT GG CC

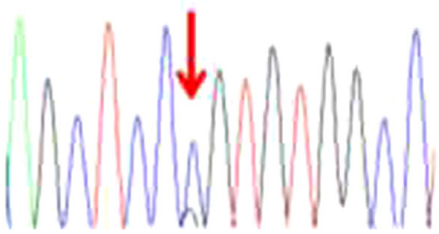

$\mathrm{E}$

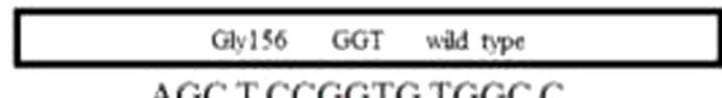

AGC T CCGGTG TGGC C

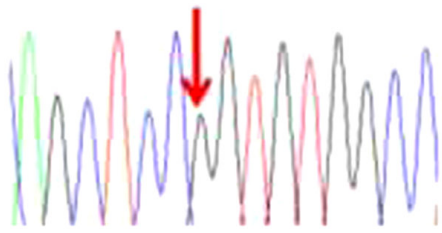

Figure 3

MEN1 gene analysis. Genomic analysis of the MEN1 gene using DNA extracted from (A) patient's oral mucosa, $(B, C)$ patient's 28 -year-old and 21-year-old son's peripheral blood leukocytes respectively, (D) patient's autopsy pituitary tumor and (E) normal subject's peripheral blood leukocytes. Arrows indicate the site of the mutation. 


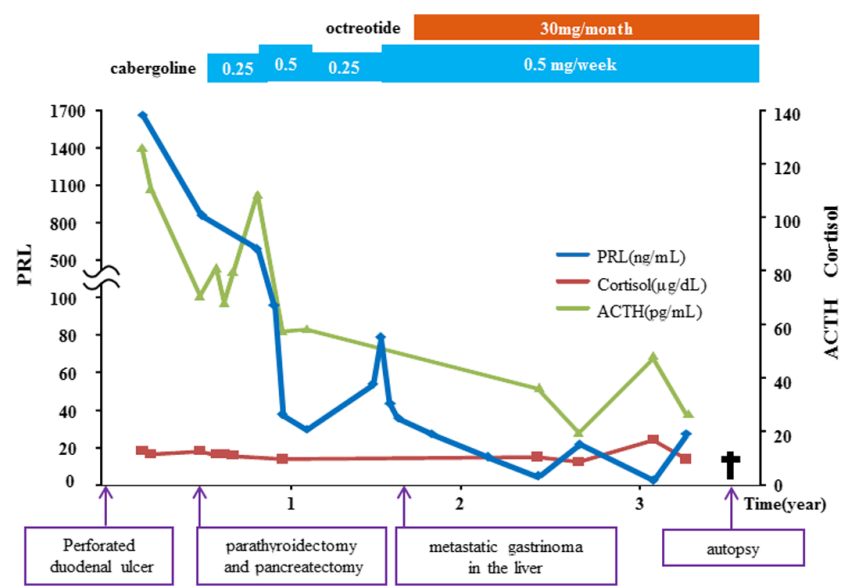

Figure 4

Clinical courses.

cortisol and plasma ACTH levels and morning plasma ACTH and serum cortisol levels were not suppressed (Table 2). During an 8-mg dexamethasone suppression test, plasma ACTH levels were weakly suppressed and serum cortisol levels were suppressed (Table 2). These results strongly suggested autonomous ACTH secretion from the pituitary tumor. However, we also suspected the possibility that the pancreatic tumors might ectopically secrete ACTH before the surgical removal of the pancreas, because the association between the Zollinger-Ellison syndrome and Cushing's syndrome has been reported previously (6).

After the diagnosis, parathyroidectomy and total pancreatectomy were performed. Histological and immunohistochemical analysis revealed that there were 44 gastrin-producing tumors in the resected pancreas, and that the maximum tumor size was $6 \mathrm{~cm}$ in diameter (Fig. 2C). The tumors were well-differentiated endocrine carcinomas of the pancreas with lymph node metastasis (TNM classification and Stage IIIb: T3 N1), and the
Ki-67 index was below 1\%. According to the WHO classification 2010, the tumors were classified as NET G1. Immunohistochemical analysis also demonstrated that the tumors did not produce ACTH. This result indicated that ACTH was not secreted ectopically from the pNET. Therefore, we decided that there was no association between the Zollinger-Ellison syndrome and Cushing's syndrome, and the pituitary tumor was strongly suspected to be a plurihormonal adenoma secreting PRL and ACTH in this case.

\section{Investigation}

\section{Study before autopsy}

MEN1 gene analysis The genomic DNA was extracted from the oral mucosa of the patient and the peripheral blood leukocytes from the patient's son using the Maxwell 16 DNA Purification Kit (Promega). Normal subject's genomic DNA was extracted from peripheral blood leukocytes. All coding regions of the MEN1 gene were sequenced using a BigDye Terminator v3.1/1.1 Cycle Sequencing Kit and an ABI PRISM 3130 GeneticAnalyzer (Applied Biosystems). A heterozygous germline mutation (Gly156Arg) in exon 3 of MEN1 was observed both in the patient and the patient's sons (Figs 1 and 3A, B, C).

\section{Treatment}

Clinical courses of medical treatment administered prior to trans-sphenoidal surgery are shown in Fig. 4. Medical treatment with cabergoline was initiated at a dose of $0.25 \mathrm{mg} /$ week in expectation of tumor shrinkage because the pituitary tumor invaded the cavernous sinuses. Six months later, serum PRL levels had significantly decreased to $37.8 \mathrm{ng} / \mathrm{mL}$ and plasma ACTH levels had slightly decreased to $57.6 \mathrm{pg} / \mathrm{mL}$. However, MRI of the pituitary
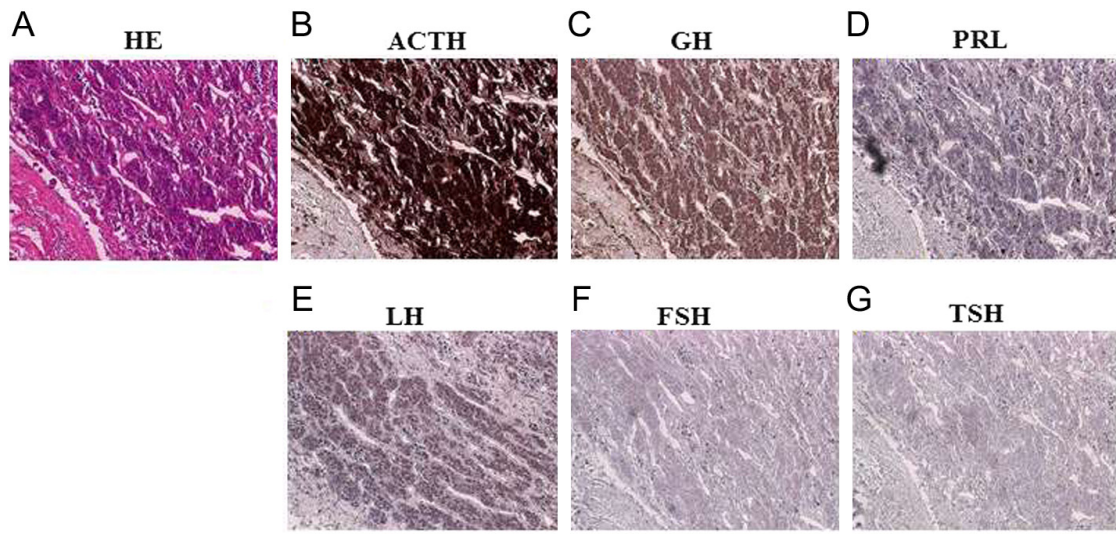

Figure 5

Histopathological and immunohistochemical analysis. (A, B, C, D, E, F and G) Histopathological and immunohistochemical analysis of the autopsy pituitary tumor. 

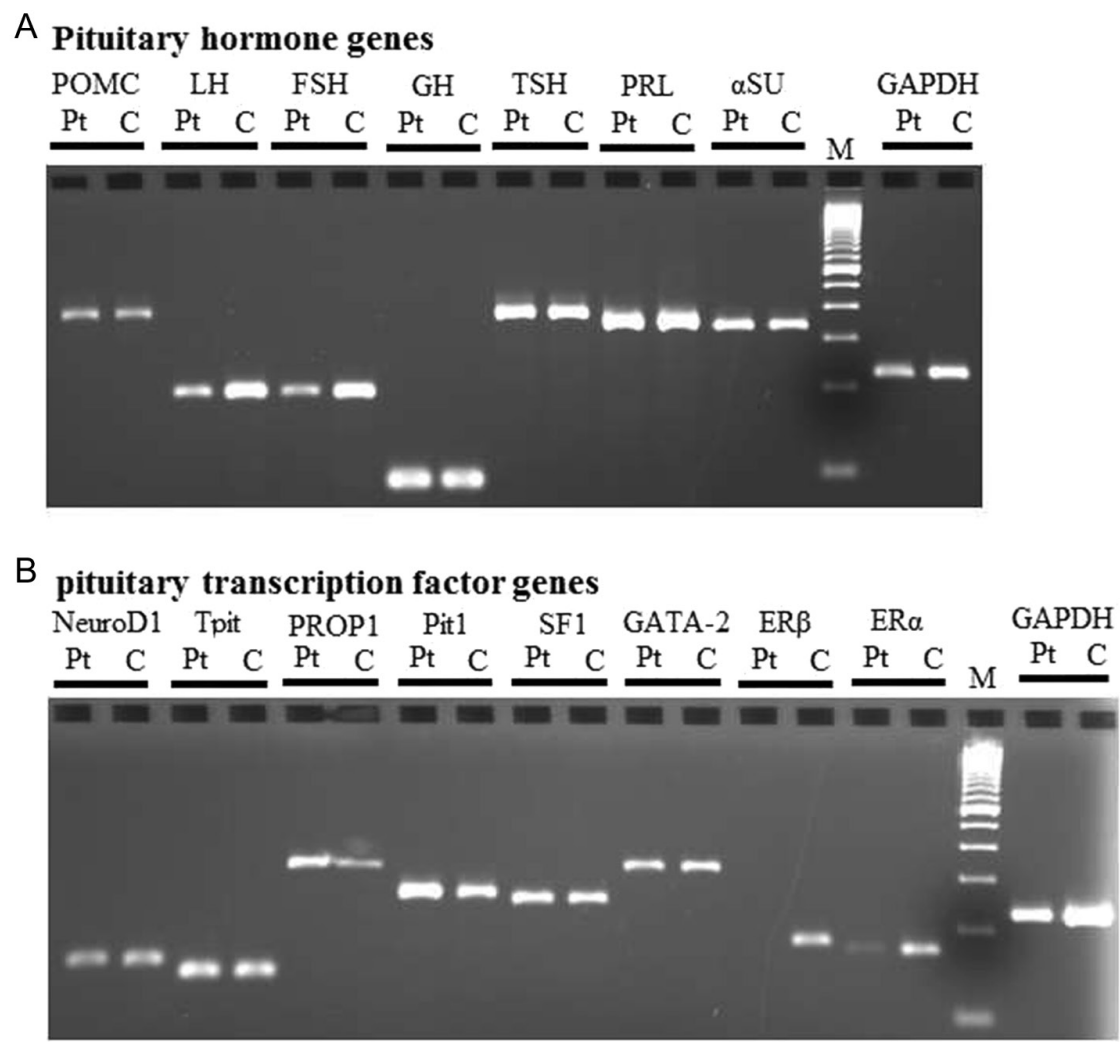

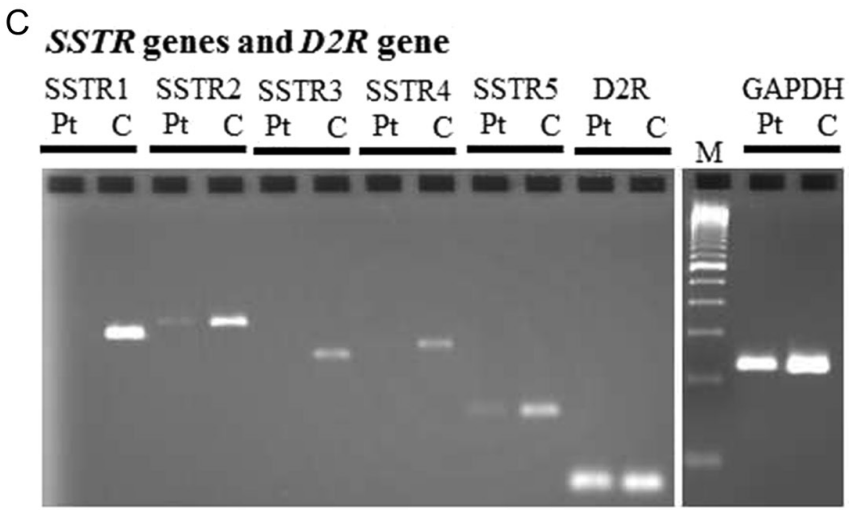

after 6 months of treatment revealed no decrease in the volume of the pituitary macroadenoma. Thus, the dose of cabergoline was increased to $0.5 \mathrm{mg} /$ week. Eighteen months after the total pancreatectomy, metastatic gastrinoma emerged in the liver, and octreotide was initiated at a dose of $30 \mathrm{mg} / \mathrm{month}$. We intended to increase the cabergoline dose in expectation of pituitary tumor shrinkage, but because the liver metastasis of gastrinoma could result in poor outcome, we decided that pituitary hormone PRL and ACTH control could be enough to stabilize the patient's condition. After the addition of octreotide, serum PRL and plasma ACTH levels further

\section{Figure 6}

RT-PCR analysis. (A) RT-PCR of pituitary hormone genes. (B) RT-PCR of pituitary hormone genes. (C) RT-PCR of SSTR genes, D2R gene. decreased to $5.1 \mathrm{ng} / \mathrm{mL}$ and $19.7 \mathrm{pg} / \mathrm{mL}$ respectively. As plasma ACTH levels normalized, the hyperpigmentation observed before the initiation of medical treatments was abolished.

\section{Outcome and follow-up}

Before transsphenoidal surgery for the pituitary tumor, the patient died of liver dysfunction due to multiple liver metastasis of gastrinoma, 3 years after the first visit to our hospital. Autopsy was performed and the results are as follows. 
Table 3 PCR primers.

\begin{tabular}{|c|c|c|c|}
\hline Name & & Primers & PCR products $(\mathrm{bp})$ \\
\hline \multirow[t]{2}{*}{ POMC } & Forward & 5'-AAGTGCGTGGCTGGTGCCTGGAGAGCAGCC & 412 \\
\hline & Reverse & 5'-TACACCTTCACTGGGCGCCGCTTCTTGCCC & \\
\hline \multirow[t]{2}{*}{$L H$} & Forward & 5'-GTCTCCTTCCCTGTGGCTCT & 203 \\
\hline & Reverse & 5'-CCTTTATTGTGGGAGGATCG & \\
\hline \multirow[t]{2}{*}{ FSH } & Forward & 5'-CTGACCAACATCACCATTGC & 202 \\
\hline & Reverse & 5'-AATCTGCATGGTGAGCACAG & \\
\hline \multirow[t]{2}{*}{ GH } & Forward & 5'-CAGCTCACCTAGCTGCAATG & 86 \\
\hline & Reverse & 5'-AAGGCACTGCCCTCTTGAAG & \\
\hline \multirow[t]{2}{*}{ TSH } & Forward & 5'-ATGCTTTTTTGGCCTTACATGTGGGCAAGCG & 391 \\
\hline & Reverse & 5'-GACAGAAAATCCTACCAGATAAGACTTCTG & \\
\hline \multirow[t]{2}{*}{$P R L$} & Forward & 5'-CTTTCTGAGCCTGATAGTCAGCATATTGCG & 360 \\
\hline & Reverse & 5'-CAGTTGTTGTTGTGGATGATTCGGCACTTC & \\
\hline \multirow[t]{2}{*}{$\alpha S U$} & Forward & 5'-TACAGAAAATATGCAGCTATCTTTCTGGTC & 343 \\
\hline & Reverse & 5'-TTTAAGATTTGTGATAATAACAAGTACTGC & \\
\hline \multirow[t]{2}{*}{ NeuroD1 } & Forward & 5'-GCCCCAGGGTTATGAGACTA & 160 \\
\hline & Reverse & 5'-GCTCCTCGTCCTGAGAACTG & \\
\hline \multirow[t]{2}{*}{ Tpit } & Forward & 5'-TGAGCACTATTCGGGTCTCC & 145 \\
\hline & Reverse & 5'-GGAAGTCCAGCTGTCAGGTC & \\
\hline \multirow[t]{2}{*}{ Prop1 } & Forward & 5'-TCAGCCTTTGGGAGGAACCAGTACCCCGAC & 348 \\
\hline & Reverse & 5'-GGCTGGGTGCAAGGTAGGGTACCAGTCCTC & \\
\hline \multirow[t]{2}{*}{ Pit1 } & Forward & 5'-CACCCAGACAAATGTTGGGGAGGCCCTGGC & 268 \\
\hline & Reverse & 5'-ATTCTGTTCTCCAAAGTGTCTCTCCAGAGC & \\
\hline \multirow[t]{2}{*}{ SF1 } & Forward & 5'-TGTCTGCCTCAAGTTCATCA & 260 \\
\hline & Reverse & 5'-TTTCGATGAGCAGGTTGTTG & \\
\hline \multirow[t]{2}{*}{ GATA2 } & Forward & 5'-TCACTGACGGAGAGCATGAA & 340 \\
\hline & Reverse & 5'-TCTGCCCATTCATCTTGTGG & \\
\hline \multirow[t]{2}{*}{$E R \beta$} & Forward & 5'-TGTATGCGGAACCTCAAAAG & 186 \\
\hline & Reverse & 5'-GATATCCCGATGCGTAATCG & \\
\hline \multirow[t]{2}{*}{$E R \alpha$} & Forward & 5'-AACAGGAGGAAGAGCTGCCA & 173 \\
\hline & Reverse & 5'-GCAGCTCTCATGTCTCCAGC & \\
\hline \multirow[t]{2}{*}{ SSTR1 } & Forward & 5'-CTGCCCATCGTGGTCTTCTC & 308 \\
\hline & Reverse & 5'-AGCTGCACCACGTAGAAAGG & \\
\hline \multirow[t]{2}{*}{ SSTR2 } & Forward & 5'-ACCAGCATCTTCTGCCTGAC & 339 \\
\hline & Reverse & 5'-GATTCCAGAGGACTTCACCTTG & \\
\hline \multirow[t]{2}{*}{ SSTR3 } & Forward & 5'-GAGCACCTGCCACATGCAGT & 252 \\
\hline & Reverse & 5'-GGCATCCAGCAGAGCACGAA & \\
\hline \multirow[t]{2}{*}{ SSTR4 } & Forward & 5'-ATCGCCATCTTCGCAGACAC & 276 \\
\hline & Reverse & $5^{\prime}$-CCAGCAGAGCACAAAGACGA & \\
\hline \multirow[t]{2}{*}{ SSTR5 } & Forward & 5'-GTGACAACAGGACGCTGGT & 156 \\
\hline & Reverse & 5'-TGGTGACGGTCTTCATCTTG & \\
\hline \multirow[t]{2}{*}{$D 2 R$} & Forward & 5'-TCCTGAACTTGTGTGCCATC & 80 \\
\hline & Reverse & 5'-GGAGCTGTAGCGCGTATTGT & \\
\hline \multirow[t]{2}{*}{ GAPDH } & Forward & 5'-GAAGGTGAAGGTCGGAGTCA & 226 \\
\hline & Reverse & 5'-GAAGATGGTGATGGGATTTC & \\
\hline
\end{tabular}

$\alpha \mathrm{SU}$; $\alpha$-subunit; D2R, dopamine receptor D2; ER, estrogen receptor; FSH, follicle-stimulating hormone; GAPDH, glyceraldehyde-3-phosphate dehydrogenase; GATA2, GATA-binding protein 2; GH, growth hormone; LH, luteinizing hormone; NeuroD1, neurogenic differentiation factor; Pit1, pituitary-specific transcription factor; POMC, proopiomelanocortin; PRL, prolactin; Prop1, prophet of Pit1; SF1, steroidgenic factor 1; SSTR, somatostatin receptor; Tpit, T-box transcription factor; TSH, thyroid stimulating hormone.

\section{Autopsy study in pituitary tumor}

MEN1 gene analysis The genomic DNA was extracted from the patient's pituitary tumor at autopsy using the Maxwell 16 DNA Purification Kit (Promega). The previously demonstrated MEN1 mutation was also confirmed to be present in the DNA extracted from the pituitary adenoma after the autopsy. There was loss of heterozygosity of the MEN1 mutation in the DNA from the tumor (Fig. 3D).

\section{Histopathological and immunohistochemical analysis}

Histopathological analysis revealed that the pituitary tumor was a single adenoma, and there were no microadenomas or multiple adenomas in the pituitary 
(Fig. 5A). Immunohistochemical analysis showed that cells were strongly positive for ACTH, positive for GH, weakly positive for $\mathrm{LH}$ and PRL and negative for TSH and folliclestimulating hormone (FSH). ACTH-positive cells were widely distributed in the tissue (Fig. 5B, C, D, E, F and G).

\section{RT-PCR analysis}

The RT-PCR results of (a) pituitary hormone genes, (b) pituitary transcription factor genes, (c) SSTR genes and $D 2 R$ gene are shown in Fig. 6 (PCR primers are shown in Table 3). The tumor expressed mRNA encoding all anterior pituitary hormones. The mRNA expression levels of pituitary transcription factor genes excluding $\operatorname{ER} \beta$ and ER $\alpha$ were approximately equal to those of normal pituitary. The mRNA expression levels of ER $\alpha$ were lower than those in normal pituitary. Although the levels of mRNA expressions of SSTR2 and SSTR5 in pituitary tumor were lower than those of normal pituitary, mRNA expression of SSTR2 was slightly higher than that of SSTR5. The levels of $D 2 R$ mRNA expression were approximately equal to that of normal pituitary.

\section{Final diagnosis}

The patient's pituitary tumor with PRL-ACTH-GHproducing plurihormonal pituitary adenoma associated with MEN1 was diagnosed.

\section{Discussion}

In this report, we describe a clinical case of a patient with MEN1 harboring plurihormonal pituitary adenoma associated with a remarkable increase in circulating ACTH and PRL concentrations. In addition, the MEN1 mutation (Gly156Arg) we detected has been reported in the Human Gene Mutation Database and in a previous paper (7). Considering that MEN1-related tumor has developed in the patient and the patient's two sons are having this MEN1 mutation in the family, it is predicted that this MEN1 mutation could be involved in the onset of MEN1.

The concurrent secretion of anterior pituitary hormones by a single pituitary adenoma is rare, except for the case of GH- and PRL-producing tumors. In particular, only a few case reports have described PRL- and ACTHproducing tumors (8) because the transcription factors on the differentiation and function of corticotrophs and lactotrophs lineage are different in the development of the pituitary (9). In general, prolactinoma is the most frequent type of pituitary adenoma observed in patients with MEN1 (2). A recent study of plurihormonality of pituitary tumors in patients with MEN1 showed that plurihormonal pituitary adenoma was observed more frequently in patients with MEN1 than that in patients without MEN1 (2); however, the combination of PRL and ACTH is rare (5). To date, no study has demonstrated a relationship between the hormonal phenotype of pituitary tumors and any specific group of mutations in patients with MEN1 (5).

Although the pituitary tumor in this case was PRLand ACTH-producing pituitary adenoma, an RT-PCR analysis revealed that the molecular phenotype of the tumor was plurihormonal pituitary tumor expressing mRNAs encoding all anterior pituitary hormones. We suggest that this might be because the pituitary tumor expressed transcription factors involved in neurogenic differentiation factor (NeuroD1)-, T-box transcription factor (Tpit) lineage (corticotroph), steroidogenic factor1 (SF1)-GATA-binding protein 2 (GATA2) lineage (gonadotroph) and pituitary-specific transcription factor1 (Pit1) lineage (somatotroph, lactotroph and thyrotroph) differentiation (9). In contrast, immunohistochemical analysis revealed that ACTH and GH were positive, whereas LH and PRL were weakly positive. The discrepancy between RT-PCR and immunohistochemistry might be due to either differences in the sensitivity of these two methods or a lack of translation of these transcripts into proteins. The discrepancy between the clinical and molecular phenotypes might be due to the lack of post-translational modification and/or a failure to secrete hormones into the bloodstream. In addition, because serum PRL levels were successfully normalized with cabergoline and octreotide during the terminal stage of the disease in the patient, restricted numbers of PRLpositive cells were observed in the autopsy specimen of the pituitary. Immunohistochemistry for $\mathrm{GH}$ was also positive in the autopsy study. On the patient's first visit to our hospital, serum GH levels were below $1.0 \mathrm{ng} / \mathrm{mL}$, but insulin-like growth factor-1 (IGF-1) levels were greater than two standard deviations above the mean value for age, suggesting that low levels of GH might have been continuously secreted into the blood. Unfortunately, we missed the opportunity to perform follow-up examinations and further confirm these findings regarding the $\mathrm{GH} /$ IGF-1 axis.

In this case, the patient did not exhibit the Cushingoid features on his first visit to our hospital and did not exhibited elevation in serum cortisol levels (in contrast to the elevation of plasma ACTH levels). We suspected that a biologically inactive 
high-molecular-weight form of ACTH might have been generated from impaired processing of POMC and/or pro-ACTH. Indeed, the ACTH immunoassay kit (Roche Diagnostics) used for the measurement of plasma ACTH concentration can detect not only intact biologically active ACTH (1-39) but also the ACTH precursors POMC and pro-ACTH.

Recent study has reported that corticotroph adenomas expressed mRNA for SSTR2, SSTR5 and D2R; and mRNA expression of SSTR2 tends to be lower than that of SSTR5, which is thought to be the cause of low effectiveness of octreotide $(10,11)$. Although various pharmacological agents, including dopamine agonist and somatostatin analogs, have been used to treat patients with Cushing's disease, these agents (with the exception of pasireotide) can normalize excessive secretion of ACTH in only a minority of the patients (12). In the case described here, treatment with cabergoline and octreotide normalized plasma ACTH levels, thereby abolishing the hyperpigmentation of the skin. We suggested that this might be because mRNA expression of SSTR2 was slightly higher than that of SSTR5 and that of $D 2 R$ was also observed in the pituitary tumor. Consistent with our clinical report, $\mathrm{T}^{\prime}$ Sjoen et al. (8) reported that the treatment with cabergoline successfully normalized excessive PRL and ACTH secretion in a patient with a PRL- and ACTH-producing pituitary adenoma. Additional clinical and basic studies will be necessary to elucidate the role of dopamine and somatostatin receptors in the regulation of ACTH secretion.

In summary, we encountered a case of a MEN1 patient with plurihormonal pituitary tumor whose plasma ACTH and serum PRL concentrations were decreased after the treatment with cabergoline and octreotide. PRL- and ACTH-secreting tumors are very rare pituitary tumors, and treatment with cabergoline and octreotide may be useful for controlling hormone levels secreted from the plurihormonal adenoma such as the one described here. Further study is needed to elucidate the mechanism of plurihormonality of pituitary tumors in patients with MEN1.

\section{Declaration of interest}

The authors declare that there is no conflict of interest that could be perceived as prejudicing the impartiality of the research reported.

\section{Funding}

This research did not receive any specific grant from any funding agency in the public, commercial or not-for-profit sector.

\section{Patient consent}

Informed consent has been obtained from the patient's son for publication of the submitted article and accompanying images. Also, informed consent for genetic testing has been obtained from the patient and from the two sons of the patient.

Author contribution statement

All authors were involved in the preparation and writing of the manuscript.

\section{References}

1 Kouvaraki MA, Lee JE, Shapiro SE, Gagel RF, Sherman SI, Sellin RV, Cote GJ \& Evans DB 2002 Genotype-phenotype analysis in multiple endocrine neoplasia type. Archives of Surgery 137 641-647. (doi:10.1001/archsurg.137.6.641)

2 Vergès B, Boureille F, Goudet P, Murat A, Beckers A, Sassolas G, Cougard P, Chambe B, Montvernay C \& Calender A 2002 Pituitary disease in MEN type 1 (MEN1): data from the France-Belgium MEN1 multicenter study. Journal of Clinical Endocrinology and Metabolism $\mathbf{8 7}$ 457-465. (doi:10.1210/jcem.87.2.8145)

3 Drange MR, Fram NR, Herman-Bonert V \& Melmed S 2000 Pituitary tumor registry: a novel clinical resource. Journal of Clinical Endocrinology and Metabolism 85 168-174. (doi:10.1210/jcem.85.1.6309)

4 Scheithauer BW, Horvath E, Kovacs K, Laws ER Jr, Randall RV \& Ryan N 1986 Plurihormonal pituitary adenomas. Seminars in Diagnostic Pathology 3 69-82.

5 Trouillas J, Labat-Moleur F, Sturm N, Kujas M, Heymann MF, Figarella-Branger D, Patey M, Mazucca M, Decullier E, Vergès B, et al. 2008 Pituitary tumors and hyperplasia in multiple endocrine neoplasia type 1 syndrome (MEN1): a case-control study in a series of 77 patients versus 2509 non-MEN1 patients. American Journal of Surgical Pathology 32 534-543. (doi:10.1097/PAS.0b013e31815ade45)

6 Ishido H, Yamashita N, Kitaoka M, Tanaka Y \& Ogata E 1994 A case of ectopic ACTH syndrome associated with Zollinger-Ellison syndrome: long-term survival with chemical adrenalectomy. Endocrine Journal $\mathbf{4 1}$ 171-176. (doi:10.1507/endocrj.41.171)

7 Concolino P, Costella A \& Capoluongo E 2016 Multiple endocrine neoplasia type 1 (MEN1): an update of 208 new germline variants reported in the last nine years. Cancer Genetics 209 36-41. (doi:10.1016/j.cancergen.2015.12.002)

8 T'Sjoen G, Defeyter I, Van De Saffele J, Rubens R \& Vandeweghe M 2002 Macroprolactinoma associated with Cushing's disease, successfully treated with cabergoline. Journal of Endocrinological Investigation 25 172-175. (doi:10.1007/bf03343983)

9 Zhu X, Gleiberman AS \& Rosenfeld MG 2007 Molecular physiology of pituitary development: signaling and transcriptional networks. Physiological Reviews 87 933-963. (doi:10.1152/physrev.00006.2006)

10 Pivonello R, Ferone D, de Herder WW, Kros JM, De Caro ML, Arvigo M, Annunziato L, Lombardi G, Colao A, Hofland LJ, et al. 2004 Dopamine receptor expression and function in corticotroph pituitary tumors. Journal of Clinical Endocrinology and Metabolism 89 2452-2462. (doi:10.1210/jc.2003-030837)

11 de Bruin C, Pereira AM, Feelders RA, Romijn JA, Roelfsema F, SprijMooij DM, van Aken MO, van der Lelij AJ, de Herder WW, Lamberts SW, et al. 2009 Coexpression of dopamine and somatostatin receptor subtypes in corticotroph adenomas. Journal of Clinical Endocrinology and Metabolism 94 1118-1124. (doi:10.1210/jc.2008-2101)

12 Feelders RA \& Hofland LJ 2013 Medical treatment of Cushing's disease. Journal of Clinical Endocrinology and Metabolism 98 425-438. (doi:10.1210/jc.2012-3126)

Received in final form 6 March 2017

Accepted 17 March 2017 